\title{
LA OCUPACIÓN ROMANA EN LA SIERRA NORTE DE SEVILLA: CASTILBLANCO DE LOS ARROYOS
}

\author{
ROMAN SETTLEMENT IN THE NORTHERN SIERRA OF \\ SEVILLA: CASTILBLANCO DE LOS ARROYOS
}

\author{
por \\ M. CAMACHO MORENO; A.M ${ }^{a}$ JIMÉNEZ FLORES; \\ M. ORIA SEGURA; M. J. PARODI ÁLVAREZ*
}

RESUMEN

Nuestro artículo muestra cómo el poblamiento romano en una zona "marginal" ayuda a comprender el carácter de las rutas secundarias de comercio y distribución de bienes durante el Alto y Bajo Imperio en la Sierra Norte de Sevilla, en la orilla derecha del Baetis, dentro de los límites de influencia del gran río como vía de comunicación. Se documentaron restos romanos, entre ellos cerámicas importadas, durante la campaña de prospección arqueológica superficial de 2002 en el término municipal de Castilblanco de los Arroyos, útiles a la hora de relacionar las rutas principales del comercio en la Provincia Baetica, sostenido a través del río, con sus líneas secundarias, trazadas en perpendicular al Valle, apuntando hacia la interacción de unas y otras y también entre las vías fluviales (el río y sus afluentes navegables) y las viae terrestres mayores y menores.

\begin{abstract}
Our paper's aim is to show how Roman settlement on a "marginal" zone may help to better understand the character of the secondary routes of commerce and distribution of goods during the Early and Late Empire in the Northern Sevillian "Sierra", on the right shore of the Baetis river, just within the limits of the great river's influence as a way of communication. Roman artifacts as imported ceramics were found during the archaeological survey's campaign of 2002 at Castilblanco de los Arroyos' municipality and might be useful to relate the main routes of the commerce in the Provincia Baetica, supported by the river, with its secondary ways, related perpendicularly to the valley, pointing the mutual interaction existing between these main and secondary routes and also between the watery ways - the river and its navigable afluents- and the major and minor viae.
\end{abstract}

Palabras claves Castilblanco de los Arroyos, romanización, poblamiento, vías terrestres y fluviales, rutas comerciales.

Key words Castilblanco de los Arroyos, romanization, settlement, land and fluvial ways, trade routes.

\footnotetext{
* Grupo de investigación "De la Turdetania a la Bética" (HUM-152), Grupo de investigación "Religio Antiqua" (HUM650) y Grupo de investigación "La Betica romana: su patrimonio histórico" (HUM-323), adscritos a los Departamentos de Historia Antigua y Prehistoria y Arqueología de la Universidad de Sevilla
} 


\section{INTRODUCCIÓN}

En los meses de julio y agosto de 2002 se realizó la prospección arqueológica superficial del término municipal de Castilblanco de los Arroyos (Sevilla), proyecto cofinanciado por la Delegación de Cultura de la Junta de Andalucía y el Excmo. Ayuntamiento de Castilblanco de los Arroyos, corriendo la dirección científica a cargo del grupo de investigación "De la Turdetania a la Bética", perteneciente al Departamento de Prehistoria y Arqueología de la Universidad de Sevilla1. La prospección proporcionó restos de ocupación romana en 22 yacimientos. Siendo materiales relativamente modestos, pueden servir para establecer la relación entre las líneas de la red principal del comercio bético, sustentado por el río, con las redes secundarias terrestres de distribución orientadas en sentido transversal, perpendicular al cauce fluvial y el valle, poniendo de relieve la interacción entre dichas redes principal y secundaria así como entre los medios fluvial y terrestre, responsables de proporcionar sustento a las líneas del comercio romano, a la par que ofrecer muestras del poblamiento en un territorio igualmente secundario respecto al valle fluvial y la costa, focos principales del asentamiento humano en época romana.

La relativa cercanía del Guadalquivir se convierte en una de las claves que explican la llegada a Castilblanco de formas de vida romanizadas, encarnadas por los hábitos alimenticios ligados a materiales como la terra sigillata. Con el eje fluvial formado por los dos mayores ríos andaluces, Guadalquivir y Genil, nos encontramos ante la más compleja arteria de circulación por vía acuática no sólo del sur peninsular en la Antigüedad, sino del conjunto de la Hispania Romana. De este modo ha sido comparado con el germano Rhin por el volumen de su tráfico fluvial y su papel en la economía y organización del territorio bético. A consecuencia de ello constatamos un notable volumen de información sobre dicho eje dual en las fuentes clásicas, lo que encuentra correspondencia en los abundantes vestigios arqueológicos sobre la presencia humana en las riberas y valle del Guadalquivir en época romana y en los diversos estudios desarrollados sobre el eje Guadalquivir-Genil y su papel económico en el Imperio.

En el Guadalquivir se hace patente -como en ningún otro río peninsular en la Antigüedad- la conjunción de los dos factores determinantes de cara a la puesta en explotación de las aguas de un cauce fluvial como medio físico y soporte material de transporte y comunicaciones: la oportunidad física y el interés económico, que combinados con la necesidad configuran lo que los latinos denominaban "commoditas". El uso de los ríos como vías navegables no está ligado exclusiva ni principalmente a su mayor o menor navegabilidad. De una parte se relaciona con el papel económico desempeñado por las tierras sometidas a su influencia. De otra, con la existencia en sus riberas de comunidades humanas que hayan alcanzado un grado tal de desarrollo socioeconómico, avanzando en la territorialización y jerarquización de sus estructuras, que les permita y les obligue a utilizar la vía acuática, no ya como un mero medio de extracción de agua para el riego y el consumo y abastecimiento directo de personas y bestias, sino como un medio de transporte relativamente fácil y cómodo, así como -y sobre todo- rápido y barato, de personas y enseres. En este sentido conocemos las condiciones físicas del Guadalquivir (Chic 1990: 21-42), relativamente desfavorables para una navegación prolongada por su curso, como ya sabemos por las propias fuentes. Ello llevaría a los habitantes de sus orillas primero a apartarse de éstas hasta una distancia prudente, para evitar la acción serpenteante del río, los efectos de su erosión y los desbordamientos del mismo. Más tarde, su sedentarización y territorialización y su economía excedentaria les exigirían y permitirían incrementar la producción, para alimentar a una sociedad en expansión y satisfacer las necesidades

1. Dentro de las líneas de investigación desarrolladas en el proyecto "Antecedentes y desarrollo económico de la romanización en Andalucía Occidental”, financiado por el MCYT (BHA2002-03447) y el II Plan Andaluz de Investigación (HUM-152). 
crecientes de un mundo cada vez más complejo, en cuyo horizonte han hecho irrupción elementos alóctonos como comerciantes orientales o la propia administración del Estado romano. Sería entonces cuando los nativos del valle del Guadalquivir habrían de acercarse al río para mejor servirse de él, como testimonia el griego Estrabón (III, 2, 3; ver Abad 1975: 20 ss.). Estas necesidades no sólo se cifran en el ansia de un mayor lujo, sino de niveles de riqueza, lo que hoy llamamos "nivel de vida" o "tren de vida" superiores. Veremos hasta qué punto se reproducen o no estos modelos en una comarca de interior que, a escasa distancia del río y en concreto, de uno de los puertos más activos en época romana, presenta las duras condiciones de las zonas de sierra.

\section{CONTEXTO ARQUEOLÓGICO}

Insertado en las primeras estribaciones de Sierra Morena, el término municipal de Castilblanco forma parte de la actual comarca "Corredor de la Plata", en el piedemonte de la Sierra Norte sevillana, limitando con los municipios de Almadén de la Plata al norte, El Pedroso y Cantillana al este, Alcalá del Río, Burguillos y Villaverde del Río al sur y, finalmente, El Ronquillo y Guillena al oeste. La orografía de la comarca se caracteriza por una sucesión de valles y sierras, muy afectados por la erosión a la que ha contribuido no sólo lo escarpado del propio relieve sino también la acción de su compleja red fluvial. Los suelos son pobres y frágiles, constituidos por tierras pardas sobre pizarra o granito, y cubiertos por las típicas formaciones mediterráneas, con predominio de un estrato arbóreo, el tradicional bosque mediterráneo de quercíneas, asociado a un estrato arbustivo representado por especies de monte como jaras, jaguarzos, palmitos o retamas, y conjugado con plantas aromáticas y vegetación riparia. El territorio de este municipio posee una cuenca fluvial de caudal permanente formada por los ríos Viar y Rivera de Cala, ambos de régimen subtropical mediterráneo de origen pluvial, que bordean respectivamente los límites este y oeste del territorio. La red fluvial consta, además, de numerosos arroyos cuyos cursos se dirigen en dirección este u oeste para desembocar en las citadas cuencas. La divisoria de aguas de estos cauces describe un trazado diagonal en dirección NO-SE que atraviesa todo el término y que constituye la principal vía natural de comunicación.

La presencia de esta vía natural situó al municipio en uno de los caminos más transitados del Suroeste peninsular a partir de época medieval, el denominado Camino de la Plata, ruta a la que se une el Camino de Santiago y eje del posterior Camino Real de Extremadura, que unía la capital hispalense con la región extremeña, activo desde el s. XV hasta principios del s. XIX (Menéndez Pidal 1951: mapa 1). Esta circunstancia, unida a la propia etimología del término plata (del vocablo árabe balât, "pavimento, empedrado"), ha conducido a la búsqueda de vestigios de antiguas vías romanas bajo este trazado.

En su descripción de la ruta Italica-Emerita tanto el Itinerario de Antonino como la Cosmographia de Rávena hacen referencia a las estaciones de Italica e Ilipa respectivamente, ubicadas al sur de Castilblanco, mientras al norte se menciona Mons Mariorum (Almadén de la Plata) en el texto más antiguo y Curiga, cerca de Monesterio (Badajoz), en el segundo, todas ellas localizaciones pertenecientes al posterior Camino Real de Extremadura. Apoyándose en estos datos y en el contraste de las referencias arqueológicas atestiguadas en dicha zona y la del actual trazado de la carretera N-630, identificada habitualmente con la vía romana, P. Sillières argumenta la coincidencia de ambos caminos, el romano y el medieval (Lám. I). Dicho itinerario correspondería a una ruta que, aprovechando la divisoria de aguas del Viar y la Rivera de Cala (sobre el establecimiento de pasos en el Viar, véase Collantes de Terán 1973), evitaría el paso por la Rivera de Huelva, de trazado más adusto, y franquearía las primeras estribaciones de Sierra Morena (Sillières 1990: 479-483). 


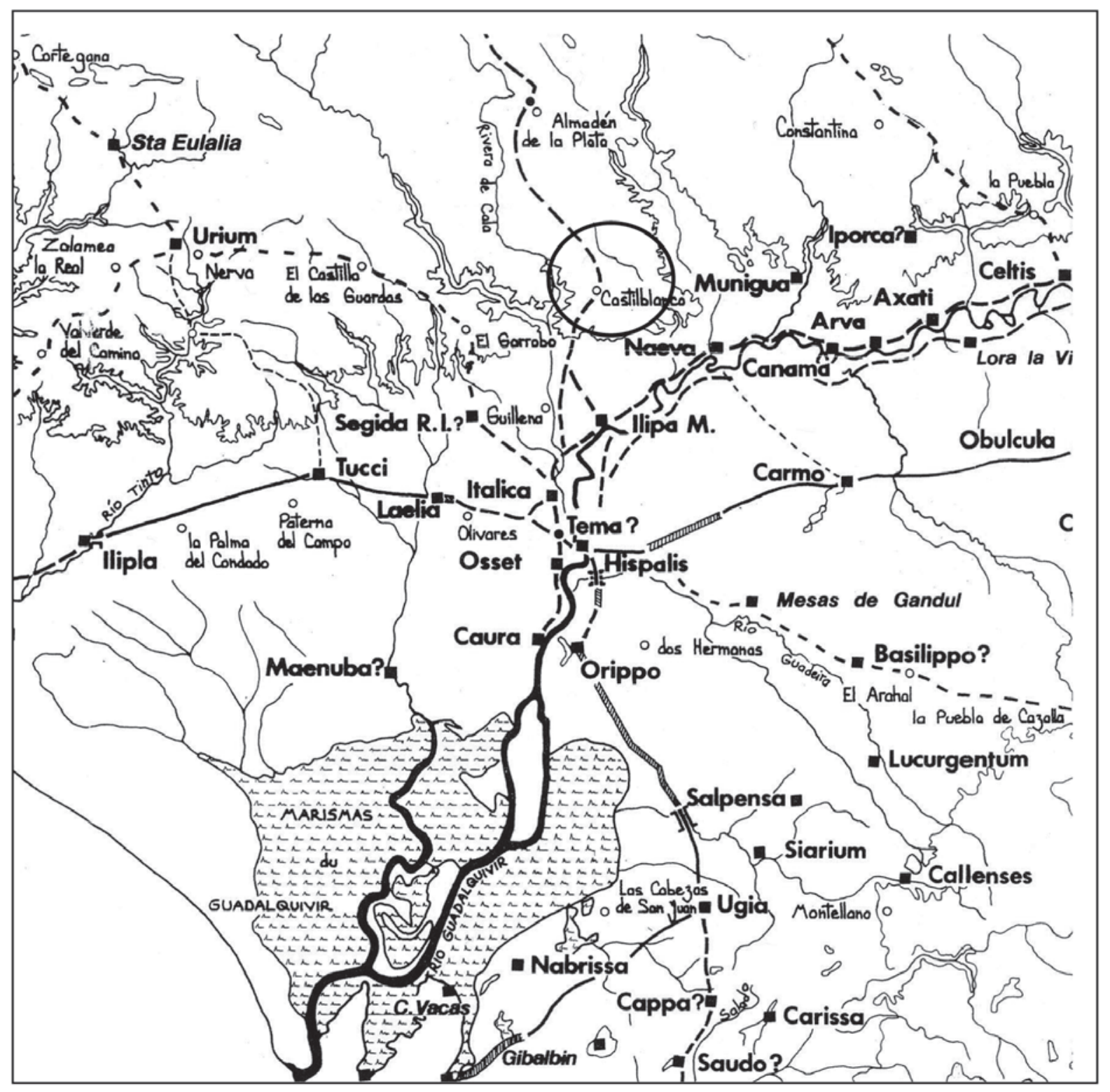

Lámina I. Reconstrucción de las vías romanas del Bajo Guadalquivir, según P. Sillières (1990).

Cultural e históricamente este territorio se relaciona con la Baeturia, situándose en sus límites; desconocemos, no obstante, hechos históricos concretos que hayan tenido como escenario estos parajes. A pesar de poseer una ubicación significativa, la ausencia de restos monumentales en la región y las controversias provocadas por la interpretación de los textos han determinado la marginación de esta zona, ausente tanto de los estudios dedicados a la Bética romana como a la propia Baeturia. Del propio término de Castilblanco sólo se tenía referencia de una inscripción votiva dedicada a la diosa Proserpina (CIL II 1044) ${ }^{2}$, conservada hasta el s. XVIII en la mampostería de la desaparecida

2. Proserpinae sanctae sacrum L(ucius) Samnius Sulla voto sanitate condemnat(us) an(imo) [l(ibens)] d(at). 
ermita de la Magdalena (López 1989: 47, n. 59), mientras los yacimientos documentados al norte del término ofrecían escasa entidad (ver infra). Las características geomorfológicas y su ubicación periférica con respecto a las feraces tierras de la Campiña determinan que las estrategias de control y explotación del medio sean muy diferentes con respecto a las articuladas en otros medios geográficos del valle del Guadalquivir y que, por consiguiente, el registro arqueológico presente ciertas peculiaridades, comunes a las áreas de sierra. Ello implica la adopción de unos enfoques metodológicos específicos a la hora de analizar los modelos de ocupación territorial a través del registro arqueológico (Ruiz del Árbol 2001).

La primera intervención arqueológica llevada a cabo en este término ha sido la prospección superficial antedicha, planteada en un principio, dada la extensión del término (32.388 Has) y las dificultades presentadas por el complejo relieve y la cubierta vegetal, como una prospección basada en la técnica de muestreo selectivo, en la que se tomaron como ejes directores las redes fluvial y de comunicaciones. Con las dificultades inherentes a trabajar dentro de límites administrativos actuales y no históricos, esta técnica nos permite conocer al menos las tendencias en la ocupación del territorio. Simplemente como tales tendencias deben considerarse las reflexiones que siguen.

La actuación permitió identificar un patrón de asentamiento para época romana que coincide a grandes rasgos con el ya establecido para los cercanos términos de Almadén de la Plata y Real de la Jara, de características geofísicas semejantes ${ }^{3}$. Los 22 yacimientos datados en época romana, o con fases de ocupación en este período, se emplazan en laderas y colinas de mediana altitud, próximas a arroyos o fuentes, y rodeados de promontorios de mayor altura que le restan visibilidad, salvo por una de sus vertientes por la que se accede a la vía de comunicación principal. Esta circunstancia determina que las mayores concentraciones se detecten en torno a los cursos del Viar y el Rivera de Cala, intercaladas en las pendientes de las sierras o en algún caso en el fondo de barrancos (Lám. II). Los restos aparecen concentrados y acumulados en las denominadas "pedrizas", majanos de piedras y materiales constructivos formados por el derrumbe de pequeñas edificaciones que hasta hace poco han servido de vivienda y cobijo a trabajadores del campo. En algunas de ellas se detectaron restos arqueológicos correspondientes a época romana, musulmana y moderna, en una amplia secuencia que ilustra la larga pervivencia de esta forma de hábitat rural.

Los asentamientos son de pequeñas o medianas dimensiones, no superando nunca $1 \mathrm{Ha}$ de superficie. Doce de ellos consisten en pequeñas construcciones circulares, ovales o cuadrangulares, a veces simplemente tramos aislados de muros o amontonamientos de forma poco definida, de piedra irregular y ladrillo con cubierta de teja, materiales de construcción que encontramos dispersos entre los restos y el entorno, junto con fragmentos de cerámica. Aunque sus dimensiones son variables, el eje mayor no suele superar los 3-5 m., dándose algunos casos de construcciones que superan los $10 \mathrm{~m}$. de longitud en su eje mayor (Cañajoso de la Rivera y Arroyo de Padres e Hijos). Suelen estar aisladas o más raramente en grupos de dos o tres a muy poca distancia entre sí, sin que puedan detectarse intentos de disposición regular. Ocupan por lo general la parte superior del cerro o la más alta de la ladera correspondiente, pero también se dan excepciones como El Toril de la Señora, con restos de al menos dos construcciones en la vaguada a orillas de un arroyo. Es frecuente que en estos recintos se acumulen materiales de distintos períodos, indicio de reutilización de las estructuras, aunque resulta muy difícil establecer si hay continuidad o simple reaprovechamiento (Lám. III).

Un grupo menor formado por ocho yacimientos escapa a esta descripción, consistiendo en concentraciones de material cerámico en una ladera de pendiente suave o un terreno llano de extensión

3. Este trabajo fue realizado por M.A. Vargas Durán, quien presentó sus resultados como Tesis de Licenciatura: Carta arqueológica de los términos municipales de Almadén de la Plata y el Real de la Jara. Tesis de Licenciatura inédita. Universidad de Sevilla 1989; y a quien agradecemos el habernos permitido la consulta del texto. 


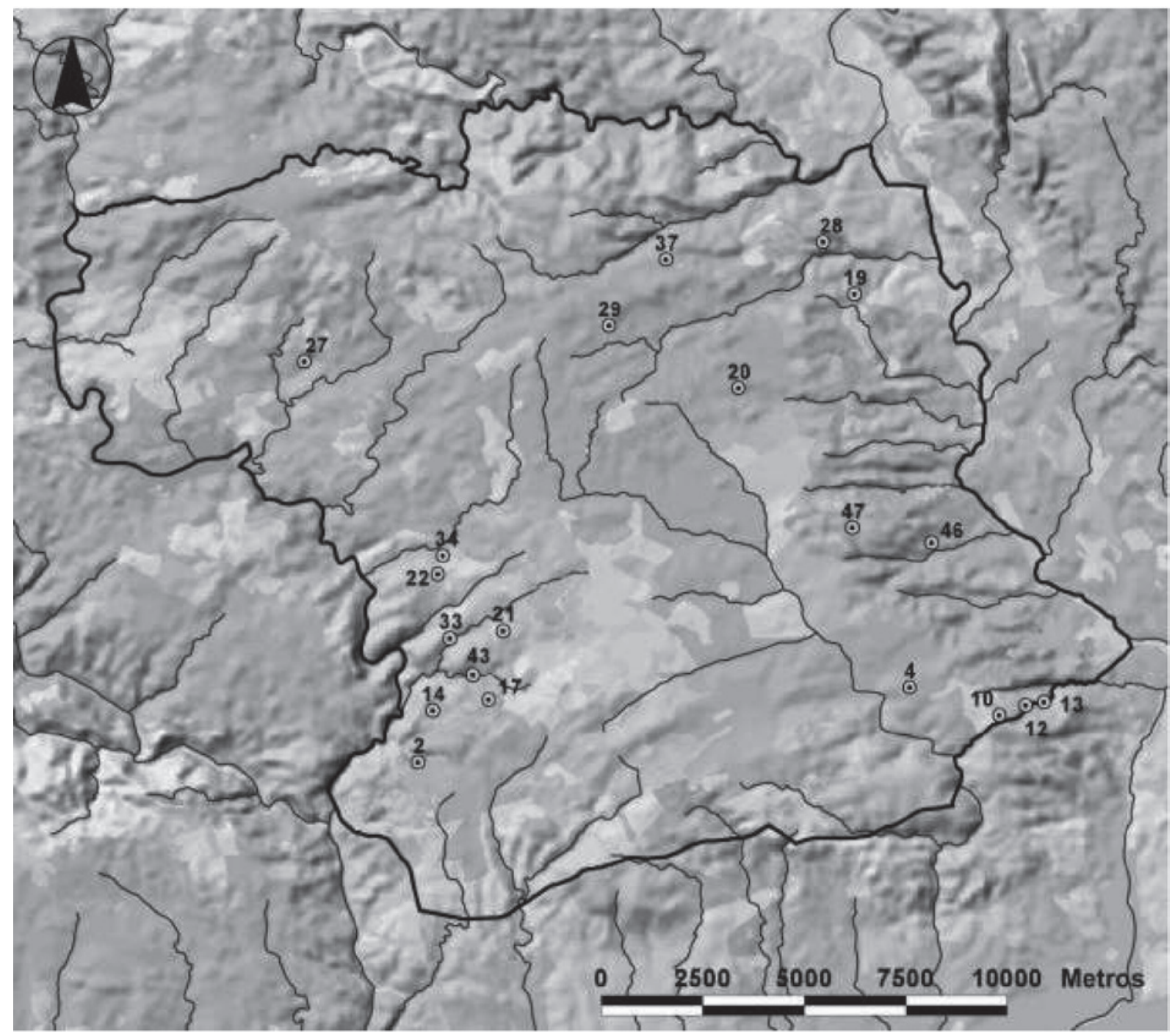

Lámina II. Yacimientos de época romana localizados en la prospección superficial del T.M. de Castilblanco de los Arroyos (Sevilla).

relativamente amplia. En algún caso como Loma Alta el terreno ha sido explanado, por lo que no podemos asegurar que fuera esa su disposición original, aunque en todo caso se encuentra en una zona llana. Por sus características y emplazamiento serían pequeñas explotaciones ganaderas o granjas, que podrían conjugarse con actividades agrícolas allí donde la calidad de los suelos o la suavidad del relieve lo permitieran. El único de ellos que se asemeja a las villae de la campiña es el complejo formado por los yacimientos vecinos n 27 y 27b, Cerro Gordo I (Los Arcos) y Cerro Gordo II, con abundante vajilla de mesa (terra sigillata de varios tipos) que evidencia un cierto refinamiento, material concentrado en dos focos separados unos $200 \mathrm{~m}$. entre sí en una extensión relativamente amplia de terreno en suave pendiente (Lám. IV).

En dos casos se pudieron identificar necrópolis, constituidas por un limitado número de sepulturas de inhumación. La de Cañajoso de Guzmán conserva restos de unas veinte fosas alargadas, algunas revestidas de lajas de piedra y con cubierta también de piedra, irregularmente dispersas en la 

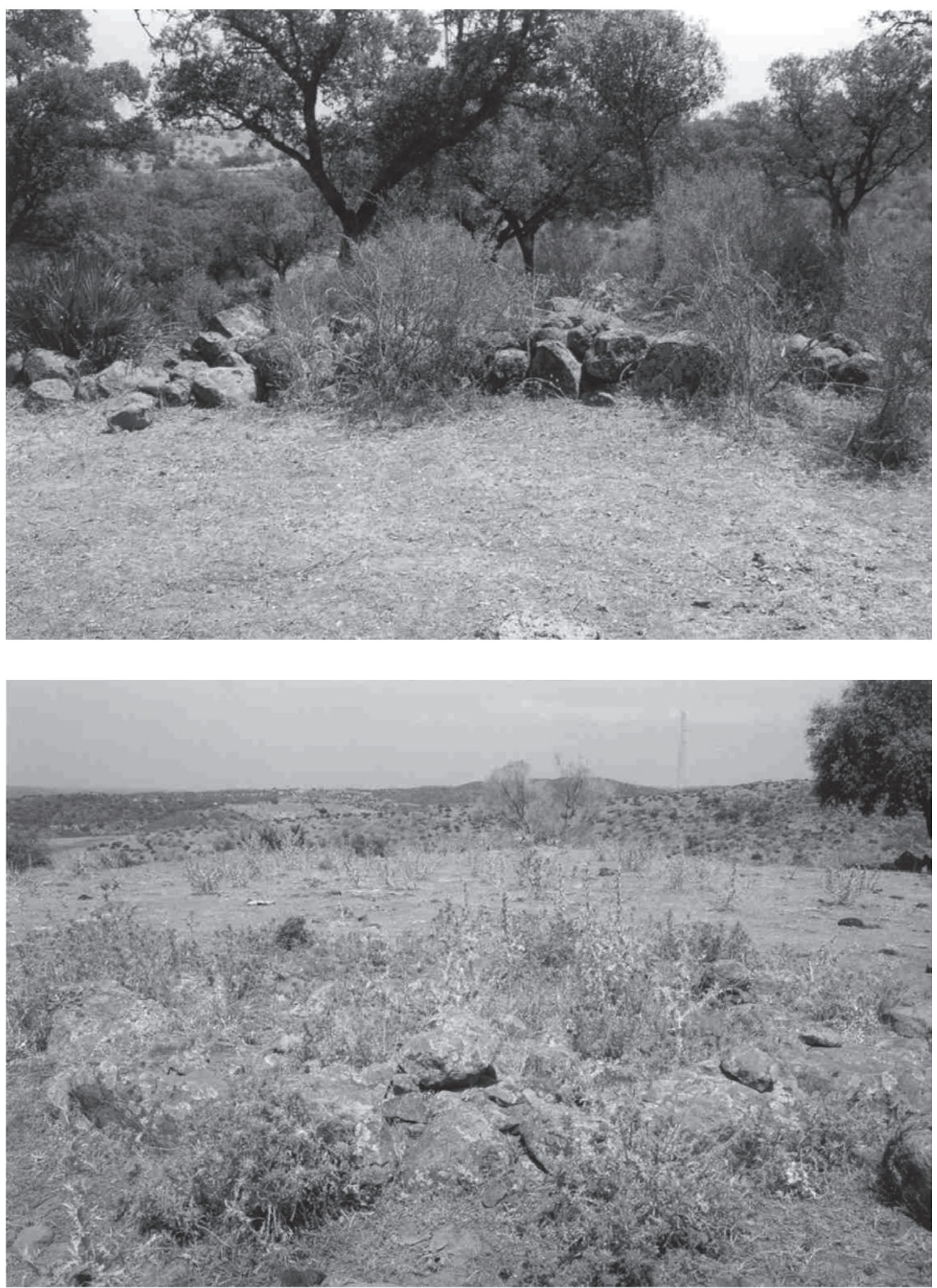

Lámina III. Vista general de las características "pedrizas": El Toril de la Señora (arriba) y Cañajoso de la Rivera (abajo)

ISSN: 1133-4525 ISSN-e: 2255-3924 


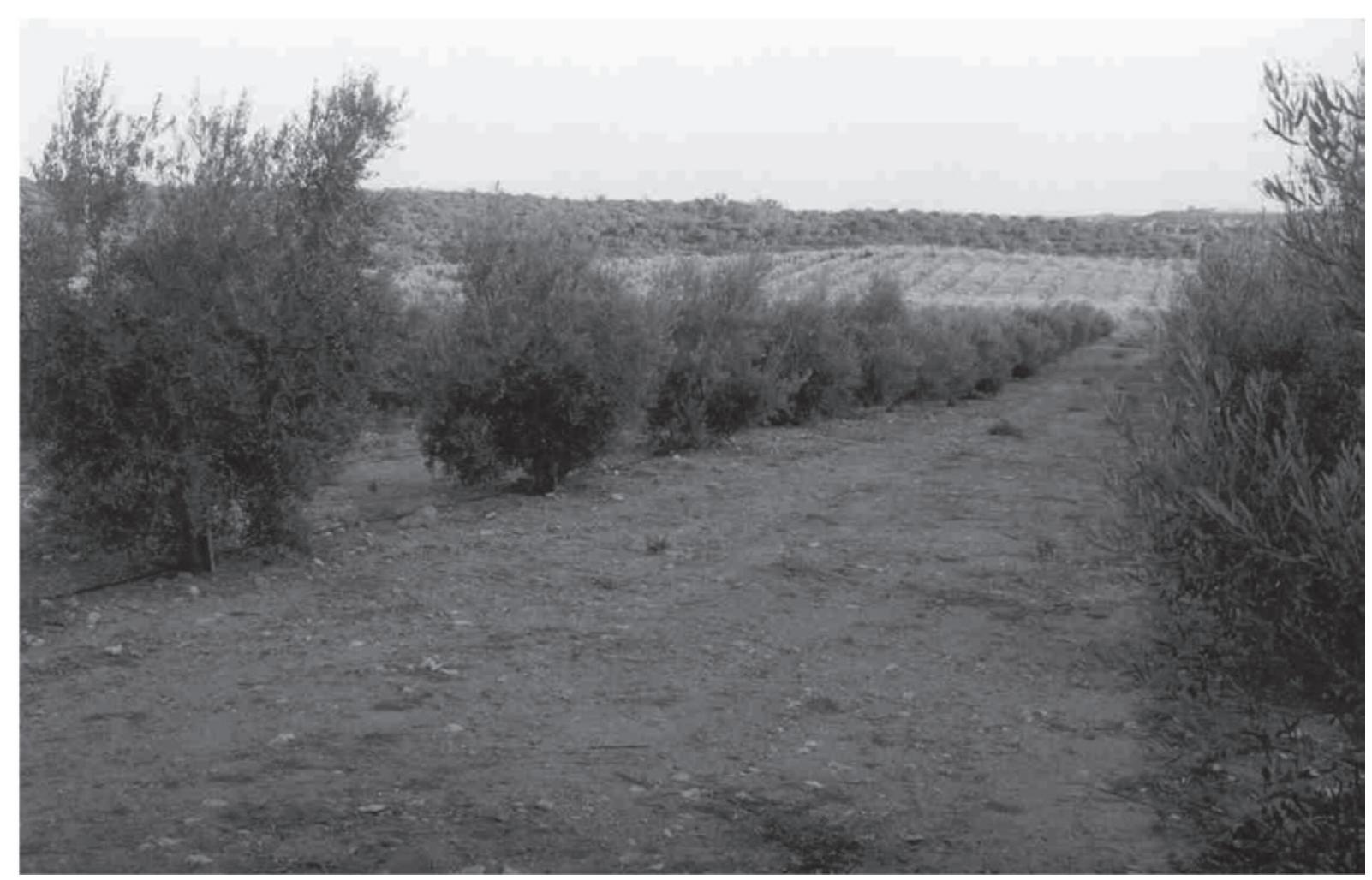

Lámina IV. Vista general del yacimiento de Cerro Gordo

cima de una elevación de mediana altura (Lám. V). La de Arroyo del Cubo, al borde de un barranco, ha sido totalmente desfigurada en su topografía por trabajos de explanación que precisamente fueron los que pusieron las tumbas al descubierto. Ninguno de los yacimientos citados presenta materiales prerromanos y sólo ocho están ocupados en distintas etapas de la Edad Media.

Por lo que respecta a los materiales recuperados, amén de los habituales elementos de construcción (tégulas, ímbrices y ladrillos), localizamos restos cerámicos no demasiado abundantes. Los fragmentos se encuentran por lo general muy rodados, afectados por la fuerte erosión y la elevada acidez de los suelos que diluyen los barnices y difuminan los perfiles. De ahí que resulte difícil darles una adscripción tipológica adecuada, que permita ajustar la cronología de los yacimientos. En su mayoría corresponden a vasijas comunes de mesa y cocina de tipología indefinida (Lám. VI), entre los que destacan fragmentos de la llamada "cerámica africana de cocina" reconocibles en tres yacimientos: Cañajoso de la Rivera, con una tapadera Hayes 196, entre 70-250 d.C.; Cerro Gordo I, con 5 fragmentos de la forma Hayes 196, 70-250 d.C., otros 2 de Lamboglia 10a, entre la segunda mitad del siglo II - s. IV y 2 más de Ostia III 267, 175-250 d.C.; y El Toril de la Señora, con un ejemplar de Ostia III 324, entre fines del s. I y mediados del II d.C. Se encuentran también grandes recipientes de almacenaje, los característicos dolia de los siglos I-II, en El Ventoso, Cerro Gordo I y La Parrilla. Más raramente, por su pésima conservación, podemos identificar fragmentos de vajilla de mesa (Lám. VII), de los que los más tempranos son algunos de "paredes finas" en Cerro Gordo I -dudosamente una forma 11 entre 50 a.C. -25 d.C. y otra forma 33b, 10 a.C. - 30 d.C.- y Arroyo del Cubo. De terra sigillata, la variedad hispánica está representada sobre todo por fragmentos de tipología dudosa o indeterminada en El Ventoso, Cerro Gordo I-II y El Toril de la Señora, aunque en Asientos de Sevilla la Vieja hay una posible Mezquíriz 19 fechable entre Claudio-Nerón y el 


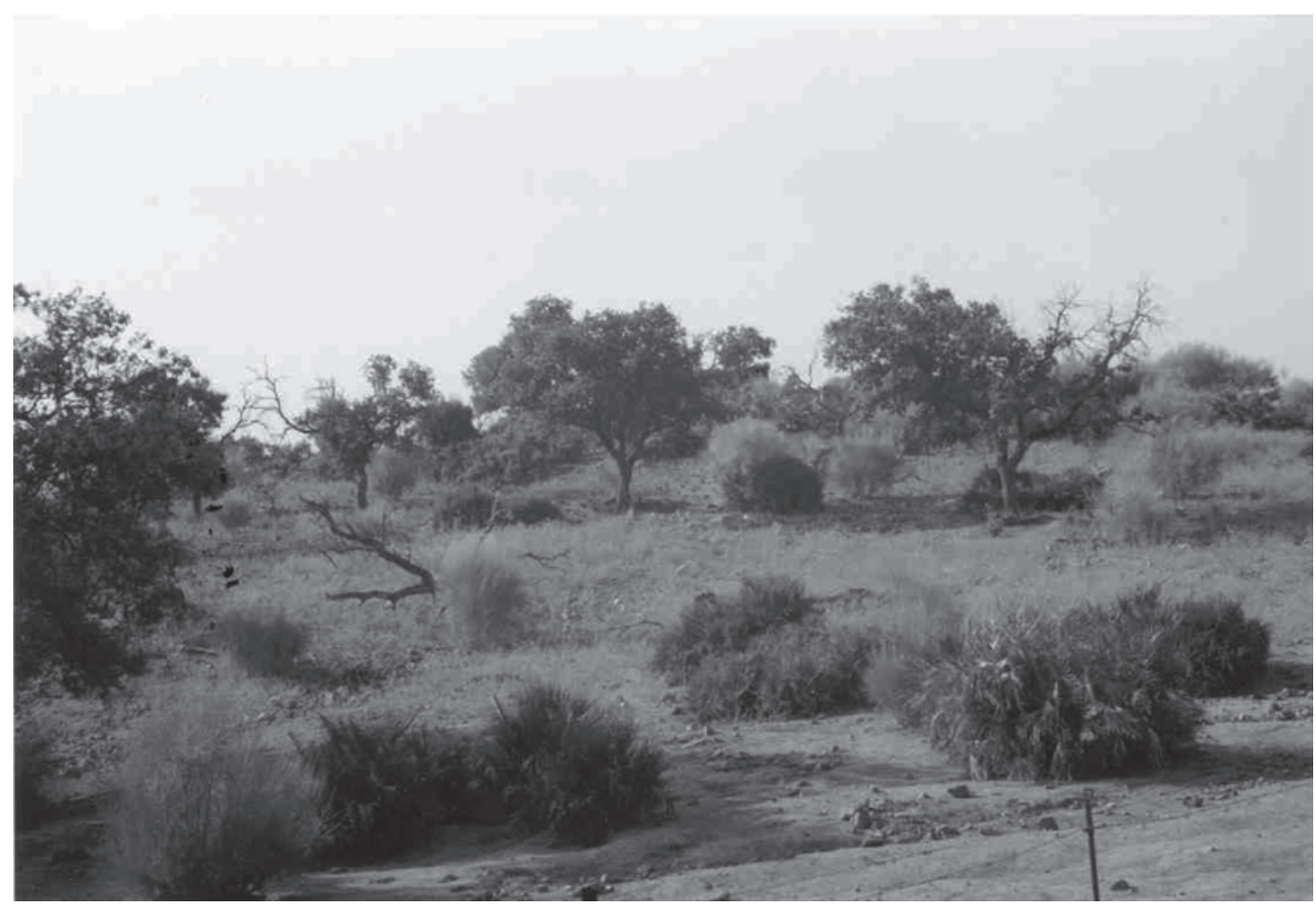

Lámina V. Necrópolis de Cañajoso de Guzmán: Vista general (arriba); detalle de una de las fosas (abajo)

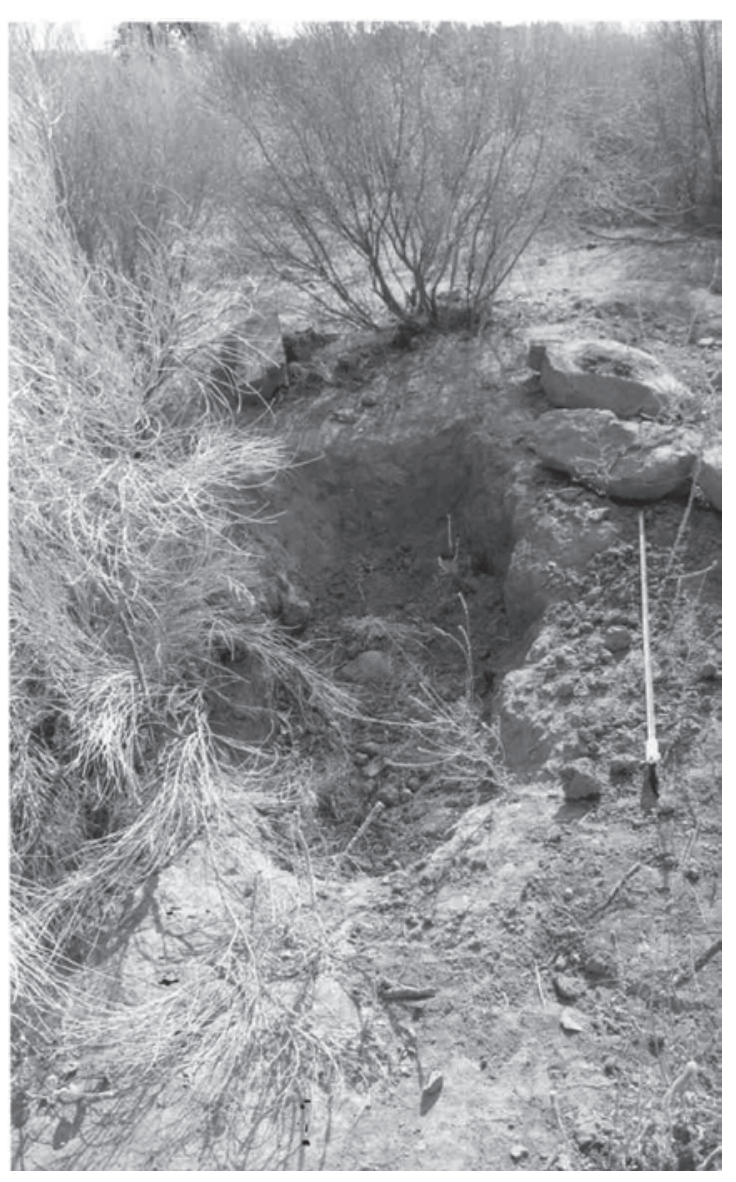

ISSN: 1133-4525 ISSN-e: 2255-3924

http://dx.doi.org/10.12795/spal.2005.i14.10 

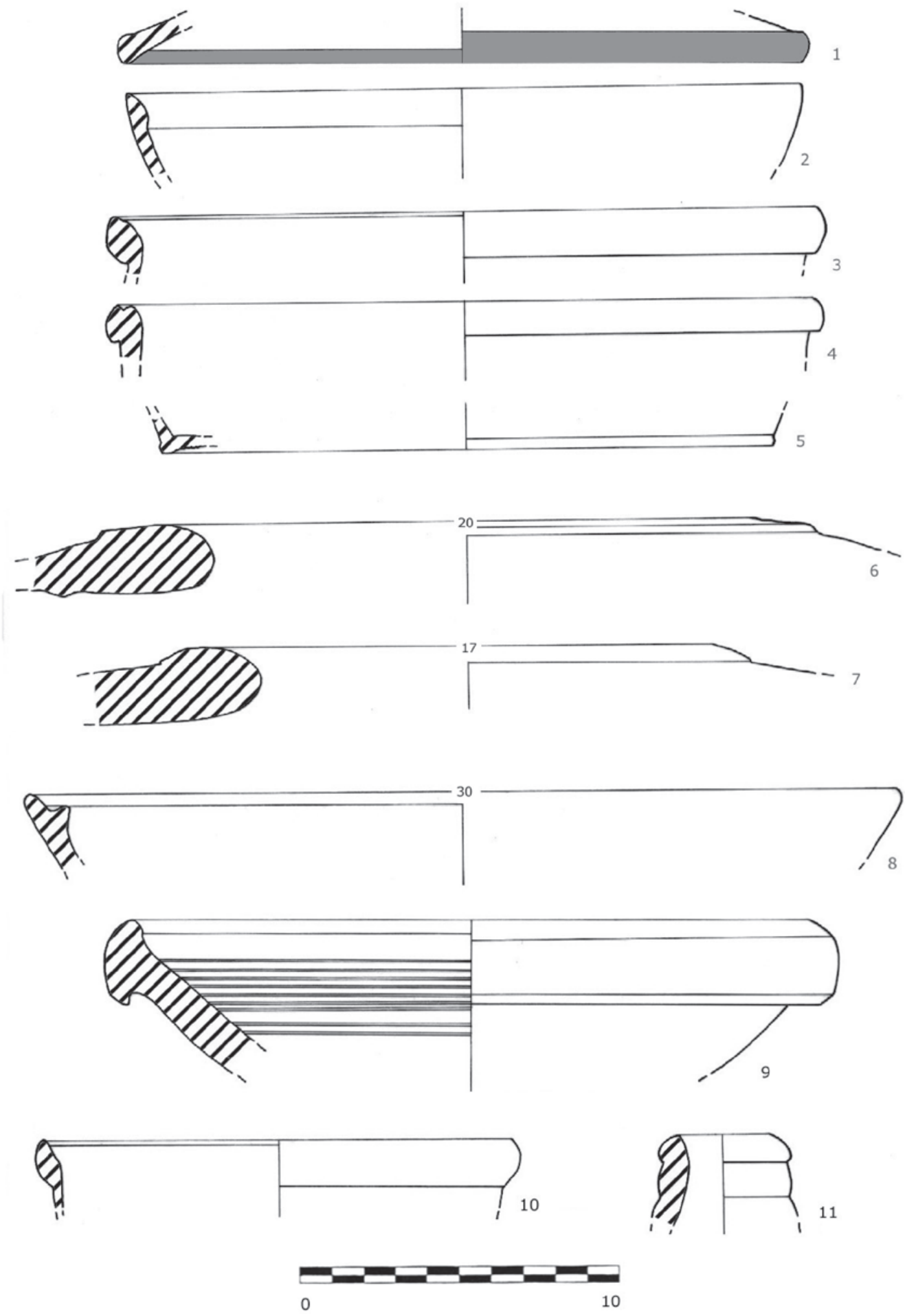

Lámina VI. Cerámica común de mesa y de cocina. Cerro Gordo (1, 2, 3, 5, 6, 10, 11); El Toril de la Señora (4); El Ventoso (7); Arroyo del Cubo $(8,9)$. 

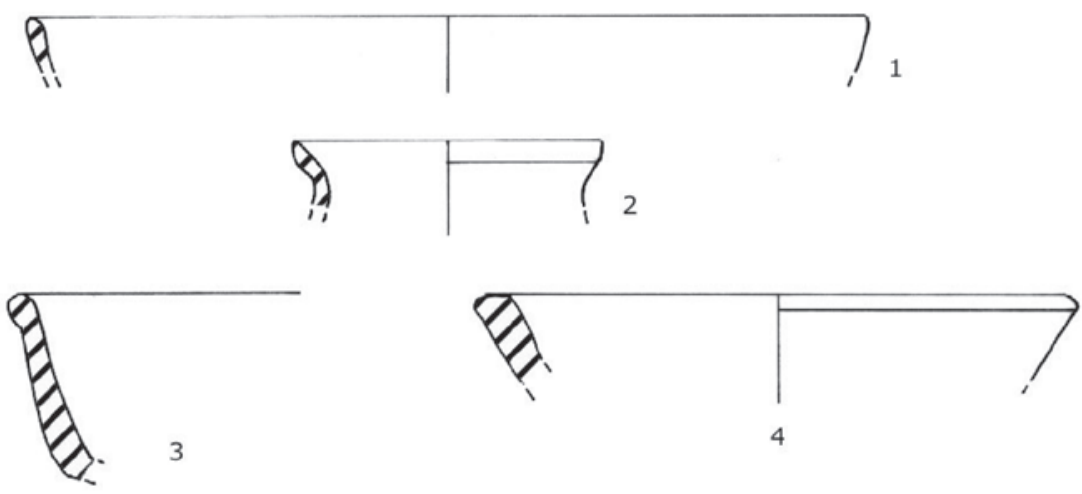

4
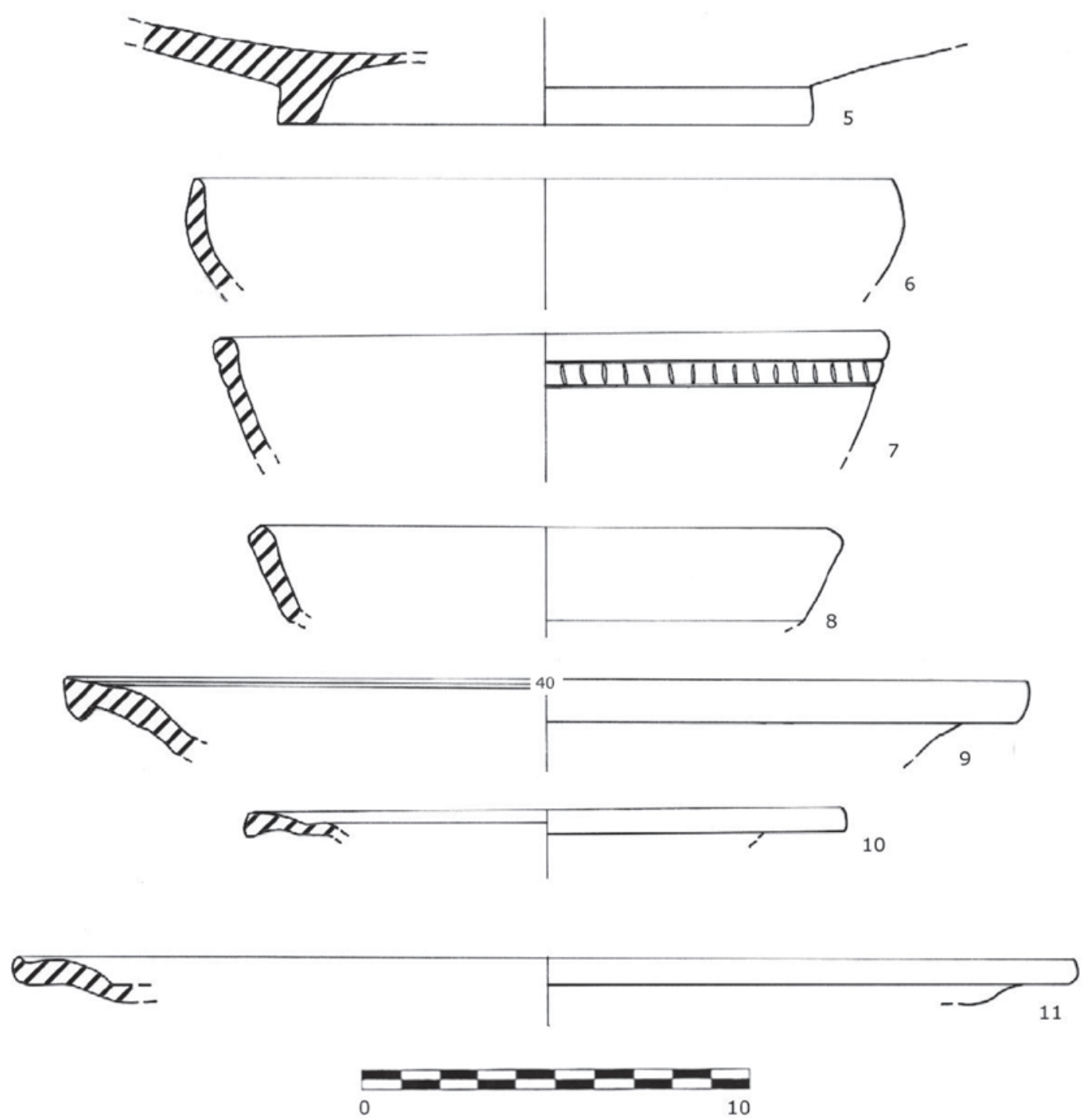

Lámina VII. Vajilla de mesa fina. Cerro Gordo (1, 2, 6, 7, 9, 10, 12); Arroyo del Cubo (3, 5); Asientos de Sevilla la Vieja (4); El Ventoso (8); Ermita de San Benito (11). 

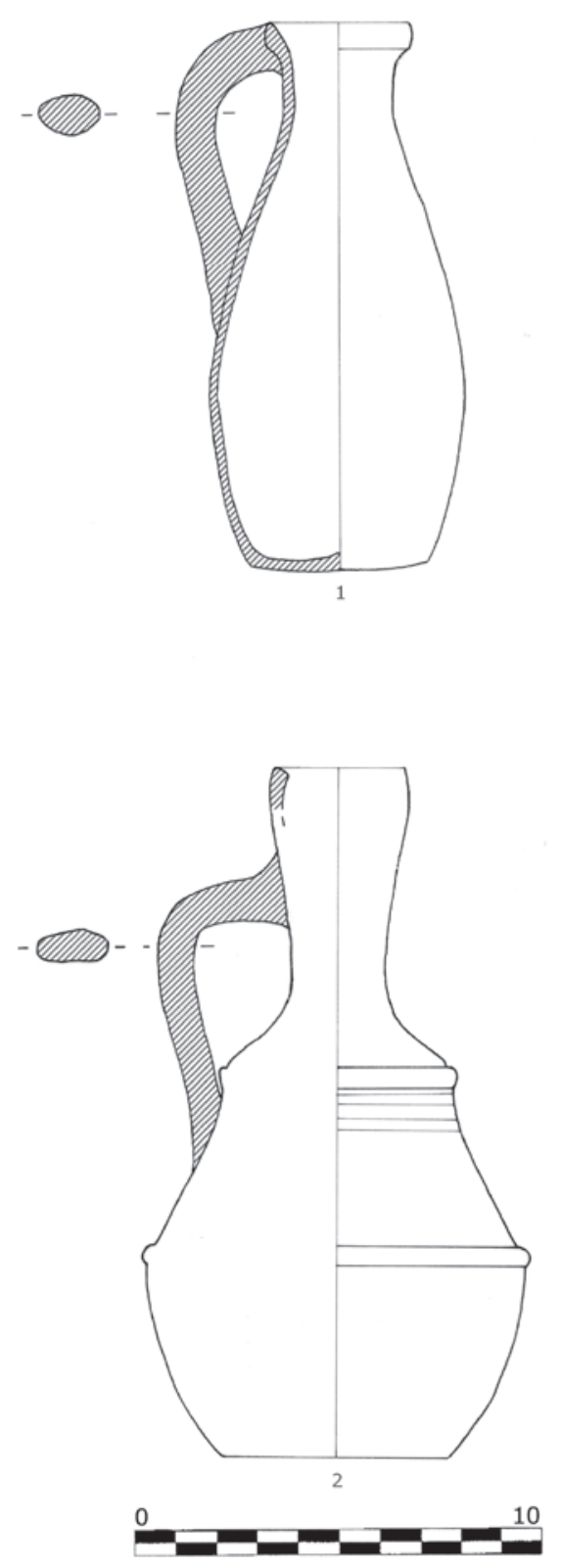

Lámina VIII. Jarritas visigodas. Necrópolis de Cañajoso de Guzmán. siglo II y en la necrópolis de Arroyo del Cubo una Drag. 18, desde época de Claudio. Encontramos además fragmentos de "clara" o africana A en El Ventoso (un fragmento de Lamb. 2 entre 100-160 d.C.), Cerro Gordo I (uno de Lamb. 3c entre 150-200 y otro de Lamb. 8 hacia 150-250 d.C.), El Toril de la Señora (posible Lamb. 20, 75-125 d.C.) y de africana D en la Ermita de San Benito (Hayes 60, 350-450 d.C.), Cerro Gordo I (3 fragmentos de Hayes 60, 350-450 d.C.) y Cerro Gordo II (Atlante 36.1, 350-400 d.C. más otros de tipología indeterminada). La necrópolis de Cañajoso de Guzmán proporcionó además en la época de su descubrimiento algunas jarritas de cerámica común en tonos blanquecinos, muy características del siglo VI d.C. (Lám. VIII). Siendo tan pocos los fragmentos de tipología reconocible y fecha precisa resulta arriesgado establecer una periodización de los yacimientos, aunque sí vemos un claro predominio del material propio de mediados del siglo I en adelante y cierta abundancia de ejemplares tardíos. La tabla incluida al final de este trabajo no puede ser otra cosa que una ordenación de los materiales localizados, usados como terminus post quem para la ocupación de los yacimientos correspondientes.

\section{EL POBLAMIENTO ROMANO EN EL TÉRMINO DE CASTILBLANCO}

La presencia de estos materiales, en particular la vajilla de mesa, en una zona de sierra y en número tan escaso, se explica a través de varios factores: la tradición cultural local, la forma de ocupación en época romana y la red de comunicaciones fluviales y terrestres establecida durante ese período histórico, que determina el papel histórico del término de Castilblanco de los Arroyos.

Los resultados de la prospección muestran una clara tendencia hacia el poblamiento rural disperso, cuyas causas analizamos a continuación. Por una parte, las condiciones naturales son poco propicias a otro tipo de asentamiento, como ciudades o al menos poblados de cierta entidad. Para el romano el monte, el bosque es lo desconocido, "lo salvaje", por oposición a "lo civilizado" que representa la ciudad (Traina 1990: 15); un medio que o bien se evita, o bien se intenta domesticar en beneficio de la población ciudadana, pero que no atrae población por sí mismo. El relieve de Castilblanco, no muy elevado pero sí de perfiles abruptos, y los suelos pobres y erosionados reducen las posibilidades de 
cultivo a las orillas de los ríos permanentes, donde tiende a concentrarse la población. Los arroyos que dan nombre a la localidad son efectivamente abundantes pero de escasa profundidad y caudal, muchos de ellos estacionales, difícilmente aprovechables como vías de comunicación o transporte incluso en pequeña escala. Sólo los dos ríos "verdaderos", Rivera de Cala y Viar, podrían aprovecharse mínimamente en ese sentido y, de hecho, sus orillas están más intensamente ocupadas que otras zonas del territorio castilblanqueño.

Tampoco existen en el término otros recursos, por ejemplo minas, que inciten al asentamiento aunque nos encontramos a pocos kilómetros de las importantes canteras de mármol de Almadén de la Plata (Canto 1977-78: 177-178; Padilla 1999: 276-277), el Pagus marmorarius que proporcionó el material para la monumentalización de Italica y otras importantes obras públicas en la Bética occidental (Rodà 1997: 161-162; eadem 1998: 115-116), e inmersos en una comarca con notables yacimientos metalúrgicos explotados desde el Calcolítico (Hunt Ortiz 1991). El control de los recursos mineros, junto con un importante foco de atracción religiosa, es lo que justifica, por ejemplo, el desarrollo algo más al Noreste y en condiciones muy parecidas de una pequeña ciudad como Munigua. Las posibilidades de explotación económica, por tanto, se reducen prácticamente a la ganadería y a los recursos propios del monte: caza, recolección de algunos frutos y miel, madera y carbón, en buena medida destinados a las ciudades más cercanas. De hecho, estos son los recursos que, hasta la época actual y salvando los avances tecnológicos en las explotaciones agrícolas y ganaderas, constituyen la base económica del municipio y los que explican la perduración hasta la segunda mitad del siglo XX de una forma de vida cuya manifestación material más evidente es la "pedriza".

La situación presenta claros contrastes con la del cercano Valle del Guadalquivir, cuya orilla derecha está jalonada de numerosos portus y varias ciudades: Italica, Ilipa Magna (Alcalá del Río), Naeva (Cantillana), Canania (Alcolea del Río), Arva (El Castillejo), Axati (Lora del Río), etc. La más próxima, Ilipa Magna, tan sólo se encuentra a $20 \mathrm{kms}$. de la zona que estudiamos, sin embargo, los primeros contrafuertes de Sierra Morena se erigen como frontera natural delimitando y configurando dos regiones de fisonomía muy diferente. Los territorios de la orilla derecha del Baetis se caracterizan por la presencia de una red de pequeñas granjas, ubicadas en las proximidades de los cursos de agua, en la que se insertan algunos establecimientos de mayor entidad, villae, con instalaciones agrícolas, talleres y construcciones suntuarias (Ponsich 1974: 114-116, 210-211). La mayor concentración de población se constata a partir de la desembocadura del Viar, donde se localizan cuatro aglomeraciones urbanas, probablemente portus (Naeva, Canania, Arva, Axati). En las tierras del interior la ocupación es escasa, debido quizás a la presencia de amplias zonas de olivar, relegando a la población a orillas del río, donde se concentraban los talleres y actividades derivadas del comercio del aceite (Ponsich 1974: 210). La afluencia de productos romanos, y con ellos quizás también de gentes de origen itálico, se detecta primero a orillas del río, donde se localizaron materiales datados en el s. I a.C. En los sitios del interior la presencia romana se remonta al s. I d.C., representada por las habituales producciones de TSH y, en mayor proporción, TSC A, prolongándose el poblamiento, al menos, hasta el s. V d.C. (Ponsich 1974: 116). Esta situación es precisamente la que evidencia el escaso material datable con cierta precisión localizado en el término de Castilblanco de los Arroyos.

No sabemos prácticamente nada sobre los límites territoriales de estos municipios, aunque es probable que su influencia llegase hasta el vecino pie de sierra. A partir de esta "frontera" se abriría una región inhóspita, no apta para el cultivo, pero adecuada para la explotación ganadera y forestal. La extensión del olivar y los cultivos de cereales a orillas del río convertía el piedemonte de Sierra Morena en un lugar privilegiado para el pastoreo de los reputados rebaños ovinos de la Bética, al que se sumarían producciones como la miel (Estrabón III, 2, 6), actividades económicas que no se traducen a nivel territorial en una ocupación humana permanente del espacio. El análisis del poblamiento romano en los términos de Almadén de la Plata y Real de la Jara, inmersos ya en plena serranía, ofrece un panorama 
que se ajusta en buena medida a estas premisas. La orografía, bastante abrupta y escabrosa, condiciona la imposición de una economía de tipo pastoril, con núcleos rurales dispersos de escasa entidad, instalados en las escasas áreas de tierra fértil de valles o pequeñas mesetas. Sólo la proximidad de las canteras de mármol o de explotaciones mineras rompe este patrón de asentamiento (Vargas 1986). La cronología de esta presencia romana es muy difusa, dada la escasa entidad de los materiales documentados o su datación imprecisa: tégulas, ladrillos, bordes de dolia, fragmentos de cerámica de cocina y algún resto de TSH, con un arco cronológico que, grosso modo, abarca desde el s. I al V d.C.; es decir, una cronología y unos materiales de características muy similares a los de Castilblanco de los Arroyos. El inicio de la explotación de las canteras de mármol, que I. Rodà sitúa en época augustea (1997: 115-116), sería el motor de esta presencia, potenciada más tarde por la construcción de la vía Italica-Emerita (Sillières 1990: 479 ss.).

El territorio castilblanqueño quedaría entonces como un territorio "marginal" desde el punto de vista administrativo, en relación con las ciudades cercanas. En las colonias es habitual marcar los límites del territorio en zonas montañosas, boscosas o estériles, que no se delimitan ni se asignan, considerándose únicamente tierras fuera del límite o abandonadas, loca extra clusa (López Paz 1994: 240-243). La situación podría ser parecida en estos municipios, cuyo estatuto jurídico no modifica las formas tradicionales de propiedad y organización social, a diferencia de lo que ocurre en las colonias. Una inscripción de la cercana Arva indica que en plena época imperial se mantienen las centuriae, entendidas como agrupaciones gentilicias de origen prerromano que la administración imperial transformaría en demarcaciones territoriales con fines de control administrativo, es decir, pagi (Chic 1993: 9-11; Sáez 1978: 257 ss.; idem 1999: 175-181; idem 2002: 406-410). Aunque en el término de Castilblanco no encontramos una organización parecida en la que encuadrar a la escasa población detectada, sí es muy probable que se trate de indígenas que mantienen la forma tradicional de ocupación y explotación, sin que pueda extrañar la poca continuidad de sus viviendas, necesariamente ocupadas por grupos familiares muy reducidos. Podríamos pensar en un reajuste territorial realizado por las autoridades romanas, con vistas a reagrupar a la población indígena en zonas de más fácil acceso. Esta actuación ya atestiguada en otras zonas de sierra (Pérez Macías y Campos 2000-2001: 204-207) conlleva el abandono de los asentamientos anteriores, por otra parte muy escasos en el término que estudiamos e igualmente dispersos.

La población originaria de la zona ha dejado sus huellas en muy pocos yacimientos con cerámicas de tradición turdetana, aunque también los materiales asignables a este período son poco característicos por los mismos problemas de conservación que afectan a la cerámica romana. Se trata de El Castillejo y Cerro Cebrón, dos atalayas naturales con amplios dominios visuales sobre el entorno, cuyas respectivas cimas concentran restos de construcción y abundante cerámica, y que podríamos caracterizar como pequeños oppida en el sentido defensivo del término. No perdamos de vista que estamos en una zona "fronteriza" también desde el punto de vista cultural, en la periferia tanto del Valle del Guadalquivir como de la Baeturia, región sometida a una fuerte influencia céltica que aún hoy plantea complejos problemas geográficos, históricos y culturales (Berrocal 1992: 29-74; Pérez Guijo 2001: 316-324). La preferencia de sus ocupantes célticos y túrdulos por un hábitat rural disperso (Estrabón III, 2, 15) explicaría en parte las escasas huellas dejadas por la población local, probablemente de filiación turdetana por su situación pero más similar a sus vecinos del Noreste en lo material (sobre el "mestizaje cultural" del pueblo túrdulo, de rasgos meseteños, turdetanos y neopúnicos sobre un sustrato orientalizante, Pérez Guijo 2001: 345). No siendo tampoco escenario de acontecimientos destacables que pudieran ser recogidos por los autores de la Antigüedad, el territorio presenta una imagen muy difuminada de su evolución histórica.

La escasez de recursos explica también la pobreza material de los restos detectados. En las condiciones descritas el nivel adquisitivo debe ser bajo y no hay demanda para los bienes importados que 
llegan Guadalquivir arriba y desde allí hacia el interior. Pero no olvidemos que en esa demanda interviene también un importante factor cultural. Las ánforas, la vajilla de terra sigillata o los ungüentarios de vidrio están ligados a unos hábitos alimenticios (véase en general sobre este tema Bats 1988; para un ámbito comparable por "poco romanizado" como Cantabria, Fernández 2001; sobre los recipientes adecuados para cada tipo de alimento según Columela, Cerchiai 2002), unas costumbres domésticas, funerarias, etc. que parecen poco arraigadas entre los habitantes de la zona, tal como los caracterizan sus viviendas y lo que en ellas encontramos. La población local parece poco romanizada desde el punto de vista cultural, de modo que no proliferan manifestaciones públicas tan características como la epigrafía, que además requiere un desembolso económico importante. Un detalle digno de mención a este respecto: hasta hoy sólo conocemos una inscripción latina procedente del término de Castilblanco de los Arroyos, una dedicatoria a Proserpina (CIL II 1044 = CILA II.1 336; ver supra nota 2) cuyo dedicante lleva un nomen, Samnius, relacionable con el Samnio en Italia, y un cognomen, Sulla, de posible origen etrusco ${ }^{4}$, (González 1991: 270-271); es decir, que podría tratarse de un foráneo. Este epígrafe, junto con otros dos de la cercana Ilipa Magna datados en el s. II d.C. (González 1982: 160-162, nº 13-14, figs. 13-14), son los únicos testimonios de devoción en la Bética a esta diosa, cuyo culto parece circunscribirse a la provincia lusitana. En esta región, el carácter infernal de la divinidad propicia la asociación con Ataecina, fenómeno evidente en el área emeritense, zona de contacto de ambos cultos en la que confluyen las tradiciones indígenas y la devoción de los nuevos pobladores latinos. En opinión de Abascal los procesos de interpretatio de ambas divinidades se localizan en la capital lusitana y al sur de la misma, por lo que no se debe ver en los testimonios de Castilblanco y Alcalá del Río huellas del culto a la diosa indígena (1995: 81-82,97). Descarta así la teoría de J. González de un culto a Ataecina en esta comarca meridional, aunque no apunta nada sobre la idea de que los tres epígrafes, dedicados por individuos de origen foráneo, procedan de un mismo centro religioso ubicado en las proximidades de Alcalá del Río (González 1982: 161).

\section{REDES Y VÍAS DE DISTRIBUCIÓN SECUNDARIAS EN LA SIERRA NORTE}

Sin embargo no se trata, como podríamos pensar, de una zona aislada. Por el contrario, constituye un camino natural entre el Valle del Guadalquivir y el del Guadiana, discurriendo por ella una vía importante que funciona a pleno rendimiento en el siglo II d.C. Las investigaciones realizadas en los últimos años en la margen derecha del Rivera de Cala (Hurtado 1993) y en el término de Almadén de la Plata (Vargas 1986; García Sanjuán 1998) confirman la presencia de un poblamiento muy anterior y la probable vigencia de esta ruta natural desde la Edad del Bronce hasta el Bronce Final y el Período Orientalizante. La mayoría de las menciones recogidas en la historiografía latina se hacen eco de esta comarca como zona de paso y tránsito. Los historiadores latinos señalan las estribaciones de Sierra Morena como el itinerario habitual seguido por los lusitanos en sus incursiones de saqueo hacia la Bética durante la etapa republicana. Con independencia del trazado concreto que siguieran los itinerarios terrestres que comunicaban el valle del Guadalquivir con Extremadura en la Antigüedad, lo cierto es que parece resultar clara su confluencia en el moderno término de Castilblanco de los Arroyos (Sillières 1990: 483-484; Corzo y Toscanos 1992: 174-177, fig. 96). Si los caminos terrestres tienen una clara funcionalidad como soporte para las necesidades locales y comarcales, no es menos cierto que sirven igualmente como soporte para la fluidez de los intercambios, agilizando el transporte de la producción de minerales (Corzo y Toscanos 1992: 177-178), acercando dicha pro-

4. También presente en nombres indígenas documentados en inscripciones de Indanha y Talavera (González: 271).

ISSN: 1133-4525 ISSN-e: 2255-3924

SPAL 14 (2005)

http://dx.doi.org/10.12795/spal.2005.i14.10 
ducción hasta la gran arteria fluvial y proporcionando de este modo salida mediante la combinación de los medios y vías terrestres y acuática (el río) a la misma, de cara a su exportación al exterior de la Bética. Puertos como el de Ilipa, el más próximo a Castilblanco, servirían así no sólo para el embarque de minerales de cara a su salida por el río, sino como centros de recepción de bienes que podrían dirigirse, ya sí a través del viario terrestre, hacia la zona menos activa económicamente hablando de la Sierra Norte de Sevilla.

Vemos por tanto el pie de sierra enlazado por caminos terrestres con una vía de comunicación y de transporte de primer orden, el río Guadalquivir, creándose una red de comunicaciones que debería teóricamente dinamizar la región. El uso de la vía fluvial del Baetis desde antes de la presencia romana en la Península Ibérica y su carácter como "definidora" del espacio meridional peninsular ibérico en la Antigüedad queda confirmado por la actuación posterior del Estado romano en su entorno. Las fuentes nos hablan de cifras relativamente elevadas en cuanto a la existencia de núcleos poblacionales en el valle del Baetis, los principales de los cuales se encontraban en relación con alguna de las vías navegables del mismo, bien la principal, bien alguna de las secundarias), así como de una más que fuerte implantación romana, cultural y física, entre el substrato indígena de la región (Ponsich 1974; Bonsor 1989: 65-88).

Es de sobra conocida la diversa realidad del río a lo largo de su curso y los cambios experimentados por el Guadalquivir desde la Antigüedad hasta nuestros días, así como los límites de la navegación y navegabilidad por el Baetis, con los obligados transbordos y cambios de embarcaciones, marítimas hasta Hispalis e Ilipa, exclusivamente fluviales aguas arriba de Alcalá del Río y progresivamente de menor porte a medida que se remontaba el río hasta Córdoba y algo más (Abad 1975: 57-82; Bonsor 1989: 89; Chic 1990: 65-81; Parodi 2001: 163-166). A partir de ahí, el transporte de hombres y mercancías debe realizarse por tierra tanto río arriba como tierra adentro, con las dificultades que conlleva y el consiguiente incremento de costes. Los precios del transporte por vía terrestre de grandes cantidades de bienes son altos, porque requieren una disponibilidad de medios no siempre al alcance de cualquiera (carros, bestias de carga), y porque el transporte de elementos frágiles como las cerámicas mediante carros supondría la pérdida de numerosas unidades, especialmente en un terreno abrupto y difícil como el serrano. Por eso no es fácil entender como las vías terrestres que pasan por las inmediaciones de Castilblanco, de las que sus pobladores debieron beneficiarse, pudieran realmente servir para sustentar un comercio regular, estable y a gran escala rumbo al interior de la Península, hacia las actuales Extremadura, Castilla y más allá. Sería la combinación de los medios fluvial y terrestre la que haría posible dicha distribución de bienes, más que la continuidad de un transporte por tierra duro, difícil y altamente costoso (Carreras 1994: 15-33; Parodi 2001: 171 ss.). La presencia de poblamiento romano y/o romanizado en el entorno (Ponsich 1974) tendría que asegurar el mercado para los escasos bienes de consumo e importación -atestiguados por la Arqueología- que hallamos en este mercado secundario, sustentados por una red de distribución igualmente secundaria frente a la principal, el río.

Lógicamente, unos fragmentos aislados de terra sigillata son muy poca documentación para hablar de un tráfico comercial continuado o de preferencia por determinados productos, pero al menos indican un flujo relativamente activo favorecido por la construcción de una vía y la cercanía tanto del puerto de entrada como de posibles destinos. La vía Italica - Emerita, construida en época flavia, atraviesa de Sur a Norte el extremo occidental del término en dirección al Mons Mariorum o más propiamente Mons Marmorum, las citadas canteras de Almadén. Con su concentración de trabajadores y personal de control venido de fuera, este núcleo industrial sí podría ser un buen destino para mercancías como las citadas. Todo ello caracteriza el término de Castilblanco de los Arroyos como una zona de paso, escasamente poblada por sus características poco atractivas de terreno difícil y escasez de recursos, algo por otra parte común a las regiones montañosas en muchas otras partes del 
Imperio. Hombres y mercancías parecen circular por ella sin dejar huellas profundas ni en la forma tradicional de ocupación y explotación, ni en las costumbres de sus habitantes.

La situación descrita puede ayudarnos a comprender cómo uno de los grandes problemas del Imperio Romano será precisamente su incapacidad para crear una estructura integrada de mercado, una [infra] estructura económica que respaldara y sostuviera la estructura política y administrativa que sí existía, que Roma sí fue capaz de crear. De este modo encontraremos "islas" de integración entre las cuales sí se desarrollan relaciones económicas fluidas, unas relaciones sostenidas en las actividades económicas primarias (agricultura, pesca, minería) y sus derivadas secundarias (actividades de transformación relacionadas fundamentalmente con la alimentación) y terciarias (comercio), todo ello sin perder de vista el peso de la tecnología y la intervención directa del Estado a la hora de mantener "vivas" y "activas" esas "islas" de desarrollo integrado. Hasta cierto punto y en menor escala, las villae podrían ejercer una función semejante en entornos rurales como el que analizamos ("islas" que no llegarán a conseguir crear una verdadera "red" de interacción e intercambios). En el Occidente se generaliza la intervención de la Annona de cara a asegurar los abastecimientos imperiales (s. I d.C.) (Chic 1994: 28 ss.; idem 1997: 31-38; idem 1998: 129-139), con la consiguiente y progresiva dependencia de la iniciativa privada respecto al Estado, que llegará mediante políticas de subvenciones y orientación de los precios al control directo de la producción y distribución de diversos objetos de comercio (Padilla 1989: 68-73; Salvador 1990: 117 ss.). Ese control apenas llega sin embargo al territorio que estudiamos, ya que el interés se concentra en el gran sector de la producción de aceite.

Uno de los esfuerzos constantes del Estado Romano con vistas a conseguir crear ese mercado integrado será el de mantener en buen funcionamiento las vías de comunicación, las rutas e itinerarios (terrestres, marítimos, fluviales). Ello explica el interés en la construcción y el mantenimiento de vías terrestres (con su complejo sistema de establecimientos auxiliares, las "mansiones"), así como la puesta en funcionamiento de los cursos fluviales (y los lagos, en una medida mucho menor en la Península Ibérica) susceptibles de ser empleados como vehículos de comunicación y transporte. Los ríos serán el eje de la articulación de esas "islas" de integración, de modo que los cursos navegables aparecen jalonados de centros urbanos y administrativos entre los que se cuentan los más importantes del Imperio, además de encontrarse en sus márgenes restos claros de su actividad económica, conjugados en las tierras del interior con una red capilar de villae (Chic 1997: 97-99). No nos atreveremos a señalar la existencia de una de tales "islas" en el moderno Castilblanco de los Arroyos, dada la modestia de los restos proporcionados por la prospección superficial. Lo que la prospección nos muestra es un poblamiento disperso dedicado a la explotación de los limitados recursos de su propio territorio. Sí podemos señalar que la proximidad al Guadalquivir y a puertos del mismo como los de Ilipa Magna, Naeva o Canania así como la existencia de un viario terrestre que servía para comunicar el interior con las riberas del Baetis beneficiaron sin duda al territorio de nuestro interés, haciéndolo partícipe, aunque sea de forma tangencial, de una red de distribución de bienes de consumo, fruto de la producción en la zona y de la importación, en época romana.

\section{BIBLIOGRAFÍA}

ABAD, L. (1975): El Guadalquivir, vía fluvial romana. Sevilla.

ABASCAL PALAZÓN, J.M. (1995), "Las inscripciones latinas de Santa Lucía del Trampal (Alcuéscar, Cáceres) y el culto de Ataecina en Hispania", AEspA 68: 31-105. Madrid.

BATS, M. (1988): Vaisselle et alimentation à Olbia de Provence (v. 350-v. 50 av. J.-C.), modèles culturels et catégories céramiques. París.

ISSN: 1133-4525 ISSN-e: 2255-3924

SPAL 14 (2005)

http://dx.doi.org/10.12795/spal.2005.i14.10 
BERROCAL, L. (1992): Los pueblos célticos del Suroeste de la Península Ibérica. Complutum, Serie Extra $\mathrm{n}^{\circ} 2$. Madrid.

BONSOR, G.E. (1989): Expedición arqueológica a lo largo del Guadalquivir. Écija.

BONSOR, G.E. (1997): Las colonias agricolas prerromanas del valle del Guadalquivir. Écija.

CANTO, A.Ma (1977-78): “Avances sobre la explotación del mármol en la España romana”, AEspA 50-51: 165-187. Madrid.

CARRERAS, C. (1994): Una reconstrucción del comercio en cerámicas: la red de transportes de Britannia. Barcelona.

CERCHIAI, C. (2002): "I recipienti per la conservazione dei cibi e i recipienti per la cottura dei cibi: Columella, Apicio, Catone e Varrone", en Tellini Santoni, B.; Cerchiai, C. y Manodori, A. (eds.): Columella. De re rustica. Civiltà agroalimentare nel Codice Vallicelliano E 39. Giornata Mondiale dell'Alimentazione 2002: 83-101. Roma.

CHIC, G. (1990): La navegación por el Guadalquivir entre Córdoba y Sevilla. Écija, (Sevilla).

CHIC, G. (1993): "Convecinos en las tierras de Lora del Río. Reflexiones en torno a una nueva inscripción axatitana de época romana”, Revista de Estudios Locales de Lora del Río 4: 7-13. Lora del Río.

CHIC, G. (1994): La proyección económica de la Bética en el Imperio Romano. Sevilla.

CHIC, G. (1997): Breve historia económica de la Bética romana (siglos I-III d.C.). Sevilla.

CHIC, G. (1998): Historia económica de la Bética en época de Augusto. Sevilla.

COLLANTES DE TERÁN, A. (1973): "Puente de Viar, ¿un empeño frustrado?", Archivo Hispalense 171-173: 117-124. Sevilla.

CORZO, R. y TOSCANOS, M. (1992): Vias romanas de Andalucía. Sevilla.

FERNÁNDEZ, F. (2001): "La romanización en la mesa. La alimentación en los núcleos urbanos de Hispania en el siglo I d.C.: el paradigma de Iuliobriga", en Hernández, L.; Sagredo, L. y Solana, J. $\mathrm{M}^{\mathrm{a}}$ (eds.): Actas del I Congreso Internacional de Historia Antigua "La Península Ibérica hace 2000 años" (Valladolid, 2000): 675-679. Valladolid.

GARCÍA SANJUÁN, L. (ed.) (1998): La Traviesa. Ritual funerario y jerarquización social en una comunidad de la Edad del Bronce de Sierra Morena Occidental. SPAL Monografías 1. Sevilla.

GONZÁLEZ, J. (1982), "Miscelánea Epigráfica Andaluza", AEspA 55: 153-172. Madrid.

GONZÁLEZ, J. (1991) (= CILA II.1): Corpus de Inscripciones Latinas de Andalucía. Volumen II: Sevilla. Tomo I: La Vega (Hispalis). Sevilla.

HURTADO, V. (1993): "Análisis y definición de los procesos culturales del II milenio a.C. en el SW peninsular", en Campos, J. y Nocete, F. (eds.): Investigaciones Arqueológicas en Andalucía 19851992: 461-470. Huelva.

HUNT ORTIZ, M.A. (1991), "Prospección arqueológica superficial en la provincia de Sevilla", $A A A$ 1989/II: 133-134. Sevilla.

LÓPEZ, T. (1989): Diccionario Geográfico de Andalucía. Madrid 1786. Ed. C. Segura, Granada.

LÓPEZ PAZ, P. (1994): La ciudad romana ideal. El territorio. Serie "La economía política de los romanos", I (dir. G. Pereira). Santiago de Compostela.

MENÉNDEZ PIDAL, G. (1951): Historia de los caminos de España. Madrid.

PADILLA, A. (1989): La Provincia Romana de la Bética (253-422). Écija.

PADILLA, A. (1999): "Consideraciones en torno a la explotación del mármol en la Bética durante los siglos I-II”, Habis 30: 271-282. Sevilla.

PARODI, M.J. (2001): Ríos y lagunas en Hispania como vías de comunicación: la navegación interior en la Hispania romana. Écija, Sevilla.

PÉREZ GUIJO, S. (2001): "La Beturia: definición, límites, etnias y organización territorial”, Florentia Iliberritana 12: 315-349. Granada. 
PÉREZ MACÍAS, J.A. y CAMPOS, J.M. (2000-2001): "El Castillo de Maribarba (Aroche, Huelva) y la política de Roma en la Baeturia", Lucentum XIX-XX: 199-208. Alicante.

PONSICH, M. (1974): Implantation rurale antique sur le Bas-Guadalquivir (I). París.

RODÀ, I. (1997): "Los mármoles de Itálica: su comercio y origen", Itálica MMCC. Actas de las Jornadas del 2200 Aniversario de la Fundación de Itálica (Sevilla, 1994): 155-180. Sevilla.

RODÀ, I. (1998): "La explotación de las canteras en Hispania”, Hispania, el legado de Roma: 113-118. Zaragoza.

RUIZ DEL ÁRBOL, M. (2001): Organización y explotación del territorio en el Noreste de Lusitania en época altoimperial. Tesis Doctoral inédita. Madrid.

SÁEZ, P. (1978): "Las centurias de la Bética", Habis 9: 257-271. Sevilla.

SÁEZ, P. (1999): “Comunidades indígenas en el Sur de la Península Ibérica: dos notas”, en Vilar, F. y Beltrán, F. (eds.): Pueblos, lenguas y escrituras en la España prerromana. Congreso de Lenguas y Culturas Paleohispánicas (Salamanca, 1999): 175-181. Salamanca.

SÁEZ, P. (2002): "Algunas consideraciones sobre el territorio de las ciudades de la Bética", en González Román, C. y Padilla Bomba, A. (eds.): Estudios sobre las ciudades de la Bética: 389-445. Granada.

SALVADOR, F. (1990): Hispania meridional, entre Roma y el Islam. Granada.

SILLIÈRES, P. (1990): Les voies de communication de l'Hispanie Méridionale, París.

TRAINA, G. (1990): Ambienti e paesaggi di Roma antica. Roma.

VARGAS, M. A. (1986): Carta arqueológica de los términos municipales de Almadén de la Plata y El Real de la Jara. Tesis de Licenciatura inédita. Universidad de Sevilla. 


\section{YACIMIENTOS ROMANOS EN CASTILBLANCO DE LOS ARROYOS}

\begin{tabular}{|c|c|c|c|c|c|c|c|c|}
\hline \multirow{2}{*}{$\begin{array}{c}\text { Períodos } \\
\text { Yacimientos }\end{array}$} & \multirow{2}{*}{\begin{tabular}{|c|} 
INDE- \\
FI-NIDOS
\end{tabular}} & \multicolumn{4}{|c|}{ ALTO IMPERIO } & \multirow{2}{*}{$\begin{array}{l}\text { SIGLO } \\
\text { III }\end{array}$} & \multicolumn{2}{|c|}{ BAJO IMPERIO } \\
\hline & & $1^{\text {a }} 1 / 2 \mathrm{~s} . \mathrm{I}$ & $2^{\text {a }} 1 / 2$ s. I & $1^{\mathrm{a}} 1 / 2 \mathrm{~S} \mathrm{II}$ & $2^{\mathrm{a}} 1 / 2 \mathrm{~s} . \mathrm{II}$ & & ss. IV-V & s. VI \\
\hline \multicolumn{9}{|c|}{ 2. Cañajoso de Guzmán } \\
\hline \multicolumn{9}{|c|}{$\begin{array}{l}\text { 4. Asientos de Sevilla la } \\
\text { Vieja }\end{array}$} \\
\hline \multicolumn{9}{|c|}{ 10. Cerro de Cuchareros } \\
\hline \multicolumn{9}{|c|}{ 13. Valle Hondo } \\
\hline \multicolumn{9}{|c|}{ 14. Cañajoso de la Rivera } \\
\hline \multicolumn{9}{|l|}{ 17. Loma Alta } \\
\hline \multicolumn{9}{|c|}{ 19. Ermita de San Benito } \\
\hline \multicolumn{9}{|l|}{ 20. El Ventoso } \\
\hline \multicolumn{9}{|l|}{ 21. Loma del Cubo } \\
\hline \multicolumn{9}{|l|}{ 22. El Granero } \\
\hline \multicolumn{9}{|l|}{ 27. Cerro Gordo I } \\
\hline \multicolumn{9}{|l|}{ 27b. Cerro Gordo II } \\
\hline \multicolumn{9}{|l|}{ 28. La Parrilla } \\
\hline \multicolumn{9}{|l|}{ 29. El Rodeo } \\
\hline \multicolumn{9}{|c|}{ 33. Arroyo Padres e Hijos } \\
\hline \multicolumn{9}{|c|}{ 34. El Toril de la Señora } \\
\hline \multicolumn{9}{|l|}{ 37. Cañada Luenga } \\
\hline \multicolumn{9}{|l|}{ 43. Arroyo del Cubo } \\
\hline \multicolumn{9}{|l|}{ 45. La Carrasca } \\
\hline \multicolumn{9}{|l|}{ 46. Los Melonares } \\
\hline $\begin{array}{l}\text { 47. Casa del Huerto } \\
\text { Baraja }\end{array}$ & & & & & & & & \\
\hline
\end{tabular}

Los yacimientos llevan el número correspondiente al catálogo de la prospección en el término de Castilblanco. El sombreado oscuro corresponde a materiales de fecha segura, el sombreado claro a materiales de tipología y fecha dudosa o demasiado amplia para concretar el momento de ocupación del yacimiento. 